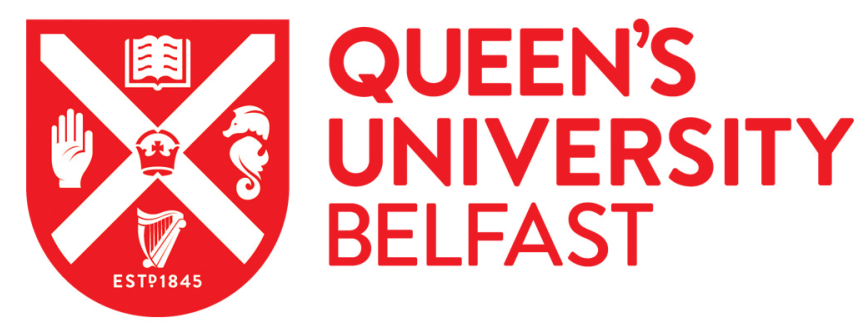

\title{
The role of salt and shear on the storage and assembly of spider silk proteins
}

Eisoldt, L., Hardy, J. G., Heim, M., \& Scheibel, T. R. (2010). The role of salt and shear on the storage and assembly of spider silk proteins. Journal of structural biology, 170(2), 413-419.

https://doi.org/10.1016/j.jsb.2009.12.027

Published in:

Journal of structural biology

Document Version:

Peer reviewed version

Queen's University Belfast - Research Portal:

Link to publication record in Queen's University Belfast Research Portal

\section{Publisher rights}

NOTICE: this is the author's version of a work that was accepted for publication in Journal of Structural Biology. Changes resulting from the publishing process, such as peer review, editing, corrections, structural formatting, and other quality control mechanisms may not be reflected in this document. Changes may have been made to this work since it was submitted for publication. A definitive version was subsequently published in Journal of Structural Biology, [VOL170, ISSUE2, (May, 2010)] DOI: 10.1016/j.jsb.2009.12.027

\section{General rights}

Copyright for the publications made accessible via the Queen's University Belfast Research Portal is retained by the author(s) and / or other copyright owners and it is a condition of accessing these publications that users recognise and abide by the legal requirements associated with these rights.

\section{Take down policy}

The Research Portal is Queen's institutional repository that provides access to Queen's research output. Every effort has been made to ensure that content in the Research Portal does not infringe any person's rights, or applicable UK laws. If you discover content in the Research Portal that you believe breaches copyright or violates any law, please contact openaccess@qub.ac.uk. 
- Lukas Eisoldt,

- John G. Hardy,

- Markus Heim,

- Thomas R. Scheibel'

\begin{abstract}
Major ampullate silk fibers of orb web-weaving spiders have impressive mechanical properties due to the fact that the underlying proteins partially fold into helical/amorphous structures, yielding relatively elastic matrices that are toughened by anisotropic nanoparticulate inclusions (formed from stacks of $\beta$-sheets of the same proteins). In vivo the transition from soluble protein to solid fibers involves a combination of chemical and mechanical stimuli (such as ion exchange, extraction of water and shear forces). Here we elucidate the effects of such stimuli on the in vitro aggregation of engineered and recombinantly produced major ampullate silk-like proteins (focusing on structurefunction relationships with respect to their primary structures), and discuss their relevance to the storage and assembly of spider silk proteins in vivo.
\end{abstract}

\title{
Keywords
}

- Spider silk;

- Protein assembly;

- Salt;

- Shear

\section{Introduction}

Orb web-weaving spiders produce a number of task-specific silk protein-based fibers. One of these fibers is assembled from proteins produced by the major ampullate (MA) silk gland. MA silk fibers are used both in the construction of the web as the frame upon which to attach the capture spiral fibers (flagelliform silk fibers coated with aggregate silk) and as a lifeline to escape from predators (Aprhisiart and Vollrath, 1994 and Lin et al., 1995). MA silk fibers of orb web-weaving spiders have impressive mechanical properties due to the fact that the underlying proteins partially fold into helical/amorphous structures yielding relatively elastic matrices that are toughened by anisotropic nanoparticulate inclusions (formed from stacks of $\beta$-sheets of the same proteins) (Gosline et al., 1999). The primary structures of MA proteins are reminiscent of amphiphilic multiblock copolymers (Exler et al., 2007, Geisler et al., 2008, Zbilut et al., 2005 and Zbilut et al., 2006), in which the repetitive sequence elements (typically composed of multiple repeats of $A_{n},(G A)_{n},(G G X)_{n}$, and $(\text { GPGXX) })_{n}$ ) are flanked by highly conserved non-repetitive (NR) amino- and carboxy-terminal domains ( Bini et al., 2004, Foo et al., 2006, Hedhammar et al., 2008, Lewis, 2006 and Rising et al., 2006). 
In common with other silk proteins, the MA proteins of Araneus diadematus spiders (ADF-3 and ADF-4) are stored at very high concentrations ( $>30$ wt.\%) without the onset of undesirable aggregation within the lumen of the spider. However, our in vitro studies of the repetitive sequence elements of recombinantly produced proteins based upon the consensus sequences of the MA proteins of Araneus diadematus spiders ( Guerette et al., 1996) without the NR terminal domains clearly demonstrate that these proteins are not soluble at such high concentrations as found in vivo ( Huemmerich et al., 2004a and Huemmerich et al., 2004b). Our findings suggest that the NR terminal domains control both the storage of the proteins (by increasing their solubility and/or deterring undesirable aggregation events) and fiber production (allowing/facilitating controlled protein assembly into fibers upon demand) (

In vivo Raman spectromicroscopy ( Lefevre et al., 2008 and Lefevre et al., 2007b) and in vitro ${ }^{13} \mathrm{C}$ NMR ( Hijirida et al., 1996) studies of the spinning dope indicate that the repetitive sequence elements adopt highly hydrated random coil and $3_{1}$-helix (polyproline II-like) secondary structures which can be easily transformed into $\beta$-sheets. We ( Huemmerich et al., 2004b) and subsequently others ( Huang et al., 2006, Ittah et al., 2007, Ittah et al., 2006, Lin et al., 2009 and Stark et al., 2007) have shown the C-terminal NR domains to adopt a predominantly $\alpha$-helical conformation in vitro. These domains have been postulated to form the outer layer of droplet-like structures observed in the spinning dope in vivo ( Jin and Kaplan, 2003, Lin et al., 2009 and Vollrath and Knight, 1999). We have also shown that the C-terminal NR domain is a prerequisite of certain supramolecular self-assembly processes (manifested in the form of fully reversible lower critical solubilisation temperature behavior) of our recombinantly produced proteins ( Exler et al., 2007).

In vivo the transition from soluble protein to solid fibers involves a combination of chemical and mechanical stimuli (such as ion exchange, acidification, extraction of water and shear forces ( Bini et al., 2004, Foo et al., 2006, Heim et al., 2009 and Vollrath and Knight, 2001) that have also been demonstrated to promote protein assembly into fibers in vitro ( Hardy and Scheibel, 2009a, al., 2008 and Rammensee et al., 2008). We were consequently interested in determining the effect of such stimuli upon the stability of our MA silk-like proteins (

A protein's solubility in aqueous solution is governed by many factors, of which, one of the most important is its primary structure, which also determines it's secondary, tertiary and quaternary structures (Levy et al., 2006, Rossmann and Argos, 1981 and SenGupta and Scheibel, 2007). The presence of other solutes (such as ions) also has an effect upon a protein's solubility in water, as they interfere with the highly ordered layer of water (known as the hydration layer) on the protein's surface (Gerstein and Chothia, 1996, Kim and Cremer, 2001, Lesk et al., 1980 and Zhang and Cremer, 2006). Low concentrations of salt tend to improve the solubility of proteins (known as 'salting in'), due to the formation of ion-rich hydration layers in the vicinity of charged and polar amino acid residues (as described by the Debye-Hückel theory), whereas high concentrations of salt tend to have the opposite effect, causing the protein to precipitate (known as 'salting out'). The magnitude of this effect is dependent upon the particular ions and usually follows the Hofmeister series, in which 'chaotropic' ions favor salting-in of proteins and 'kosmotropic' ions favor salting-out of proteins, and anions are well-known to have a much greater effect than cations (Baldwin, 1996, Geisler et al., 2008, Gurau et al., 2004, Horinek et al., 2008, Pegram and Record, 2008, Pirzer et al., $\underline{2009}$, Zhang and Cremer, 2006 and Zhang et al., 2005). 
Knight and Vollrath have investigated the MA gland of Nephila edulis spiders, finding that the physiological concentration of sodium chloride in the spinning dope in the lumen to be of the order of $150 \mathrm{mM}$, and the total concentration of salts was observed to decrease during the spinning process. They also found that as the dope flowed through the spinning duct, sodium cations were replaced by potassium cations, yet other metal cations (e.g. calcium, copper or magnesium) were almost undetectable in the lumen, duct and the naturally spun fibers. Furthermore, they observed that weakly chaotropic chloride anions are replaced with strongly kosmotropic phosphate anions (significantly increased concentrations) and sulfate anions (small increase with a relatively high level of experimental error) during the passage of the spinning dope along the spinning duct ( Knight and Vollrath, 2001). Here we investigate the effects of salts (sodium chloride and sodium phosphate) and shear on the in vitro aggregation of our recombinantly produced MA silk-like proteins, and discuss their relevance to the storage and assembly of spider silk proteins in vivo.

In this study we use recombinantly produced silk proteins based on the consensus motifs of the MA silk Aranaeus diadematus fibroin 3 (ADF3) from the garden cross spider. The repetitive core domains of our proteins are composed of two different sequence modules, denoted $A$ and $Q$, where module $A$ is a hydrophobic polyalanine-rich motif, and module $Q$ is a more hydrophilic glutamine- and glycine-rich motif (see materials and methods). In this study we use proteins containing 12 or 24 repeats of (AQ). The C-terminal NR3 domain is derived from adf3 (gi|1263286, obtained from J. Gosline, Vancouver, BC) by using PCR. This domain is mainly $\alpha$-helical and dimerises via disulfide bond formation between the single cysteine residues contained in two individual NR3 domains ( Huemmerich et al., 2004b) ( Fig. 1); therefore proteins bearing the NR3 domain are dimeric under non-reducing conditions.

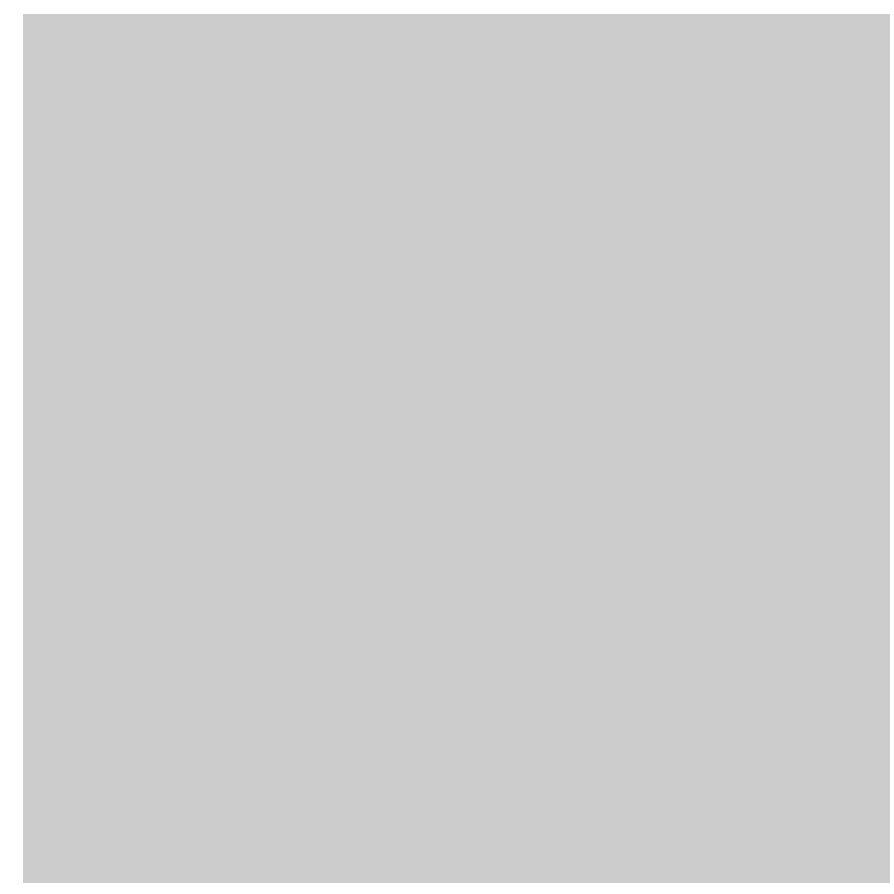

Fig. 1.

Employed recombinantly produced proteins based on the consensus sequences of the major ampullate protein (ADF-3) of Araneus diadematus spiders. (A) A schematic representation of the repetitive sequence elements $(A$, hydrophobic polyalanine-rich motif and $Q$, hydrophilic 
glutamine- and glycine-rich motif) and the C-terminal non-repetitive domain (NR3). (B) A schematic representation of the engineered and recombinantly produced major ampullate silk-like proteins composed of the elements shown above. For each protein the molecular weight in $\mathrm{kDa}$ is given in brackets. Note that proteins bearing the NR domain are dimeric due to interdomain disulfide bond formation. (C) The primary sequence of the C-terminal nonrepetitive domain (NR3) of the major ampullate protein (ADF-3) of Araneus diadematus spiders, highlighting the residues involved in salt bridges and the cysteine residue responsible for interprotein dimerization. In the (AQ) ${ }_{12} \mathrm{NR} 3(\mathrm{D} 93 \mathrm{~A})$ mutant the single aspartic acid residue is replaced by an alanine residue, inhibiting the formation of one of the two possible salt bridges.

\section{Figure options}

\section{Materials and methods}

\subsection{Cloning, protein expression and purification}

The proteins ( $\mathrm{AQ})_{12} \mathrm{NR} 3$ (dimer of $116 \mathrm{kDa}$ ), $(\mathrm{AQ})_{24} \mathrm{NR3}$ (dimer of $212 \mathrm{kDa}$ ) and $(\mathrm{AQ})_{24}$ (monomer of $95 \mathrm{kDa})$, containing the repetitive elements (A, hydrophobic polyalanine-rich motif: GPYGPGASAAAAAAGGYGPGSGQQ; Q, hydrophilic glutamine- and glycine-rich motif: GPGQQGPGQQGPGQQGPGQQ) were cloned, expressed and purified as previously reported. A D93A mutant (numbering according to the residues of the NR domain; see Fig. 1C) of (AQ) ${ }_{12} N R 3$ was obtained according to the QuikChange protocol from Stratagene (USA).

\subsection{Salt-induced aggregation assay}

Experiments were carried out in accordance with our previously described protocol (Huemmerich et al., 2004b). Prior to the experiment the proteins were dissolved in guanidinium thiocyanate solution $(6 \mathrm{M})$ and then dialyzed against $10 \mathrm{mM}$ Tris/ $\mathrm{HCl}, \mathrm{pH} 8.0,50 \mathrm{mM} \mathrm{NaCl}$. The assay was started by the addition of buffered (10 mM Tris/ $\mathrm{HCl}, \mathrm{pH} 8.0$ ) solutions of $\mathrm{NaCl}$ and $\mathrm{NaH}_{2} \mathrm{PO}_{4}$ (pH 8.0). Protein concentrations were, respectively, $8.8 \mu \mathrm{M}, 5.3 \mu \mathrm{M}$ and $4.7 \mu \mathrm{M}$ for $\mathrm{AQ}_{12} \mathrm{NR3}$ (wt and $\mathrm{D93A}$ ), $\mathrm{AQ}_{24}$ and $\mathrm{AQ}_{24} \mathrm{NR} 3$. After $1 \mathrm{~h}$ of incubation at $25^{\circ} \mathrm{C}$ the samples were centrifuged at $17700 \mathrm{~g}$ to remove any visible aggregates, and the amount of soluble protein remaining in the supernatant was determined using a UV spectrometer (NanoDrop ND1000, ThermoFischer, USA).

\subsection{Shear-induced aggregation assay}

Prior to the experiment the proteins were dissolved in guanidinium thiocyanate solution (6 $\mathrm{M})$ and then dialyzed against $10 \mathrm{mM}$ Tris/ $\mathrm{HCl}, \mathrm{pH}$ 8.0. Then the proteins were diluted into buffer containing $10 \mathrm{mM}$ Tris/ $\mathrm{HCl}, \mathrm{pH} 8.0$ with $50 \mathrm{mM} \mathrm{NaCl}$. Final protein concentrations were adjusted to $17.6 \mu \mathrm{M}$ of $A Q_{12} \mathrm{NR3}$ and $10.6 \mu \mathrm{M}$ of $\mathrm{AQ}_{24}$. The samples were incubated for $16 \mathrm{~h}$ at $25^{\circ} \mathrm{C}$ without/with rotation at $25 \mathrm{rpm}$ (Intellimixer RM-2, NeoLab, Germany). After rotation, the clearly visible aggregates were transferred onto glass slides for optical microscopy (DMI3000B, Leica, Switzerland). The samples were then centrifuged at $125000 \mathrm{~g}$ to remove non-visible aggregates, and the amount of remaining soluble protein in the supernatant was determined using a UV spectrometer (NanoDrop ND1000, 
ThermoFischer, USA). The percentage of aggregated protein was calculated as described in section 2.2 .

\subsection{Fourier transform infrared (FTIR) spectroscopic studies}

FTIR spectra of fibers were recorded on a liquid nitrogen cooled Bruker Tensor 27 FTIR spectrometer, fitted with a liquid nitrogen cooled Bruker Hyperion microscope with IR polarizers supplied by Optometrics Corporation (Ayer, MA, USA). Spectroscopy was performed on fibers formed during the previously described aggregation assay that were washed with water to remove salts, air dried and placed on highly polished optical grade calcium fluoride disks (Crystal $\mathrm{GmbH}$, Berlin, Germany). Spectra of all aggregates were recorded in absorbance mode at $21^{\circ} \mathrm{C}$, with a $4 \mathrm{~cm}^{-1}$ resolution and 60 scans (corrected for background and atmosphere using OPUS software), and polarized FTIR spectra of aggregates of $\mu \mathrm{m}$ scale (and larger) were recorded at three different orientations $\left(0^{\circ}, 45^{\circ}\right.$ and $90^{\circ}$ relative to the long axis of the fibrous aggregates) to determine if any of the secondary structural elements were aligned with the fibers.

\subsection{Transmission electron microscopy}

Prior to the experiment the proteins were dissolved in guanidinium thiocyanate solution $(6 \mathrm{M})$ and then dialyzed against $10 \mathrm{mM}$ Tris/ $\mathrm{HCl}, \mathrm{pH}$ 8.0. A droplet $(3 \mu \mathrm{L})$ was placed on pioloform-coated copper grids and the excess liquid was removed by wicking using a Kimwipe (Kimberly-Clark Corporation, USA). The grid was then stained with uranyl acetate ( $1 \%$ in water, $\mathrm{pH} 4.5$ ) and the excess liquid was removed by wicking using a Kimwipe, and allowed to dry in a dust free dessicator. The grids were viewed with a JEOL JEM-2100 transmission electron microscope (Jeol, Eching, Germany).

\section{Results and discussion}

\subsection{The effect of salt on protein aggregation}

As noted in the introduction, MA spidroins are stored in the lumen of the gland in the presence of sodium and chloride ions, and during fiber spinning these ions are exchanged for potassium and phosphate ions (Knight and Vollrath, 2001). Here we investigate the effects of chloride and phosphate anions on the in vitro aggregation of our recombinantly produced MA silk-like proteins ( Fig. 1).

Our solubility/aggregation assays in the absence of shear forces (similar to the situation of the silk proteins in the lumen of the gland) show that the extent of protein aggregation is determined by the concentration of salt. Our assays with sodium chloride (found in the lumen) indicate that the level of aggregation is low (less than 20\%) for all of the tested engineered proteins, even at extremely high salt concentrations (up to $500 \mathrm{mM}$ ); whereas in the presence of equivalent concentrations of sodium phosphate (found in the spinning duct) the level of aggregation for each protein is notably higher (up to $100 \%$ ) due to the more kosmotropic nature of the phosphate anion (Fig. 2). Therefore, weakly chaotropic chloride anions aid the long term storage of MA spidroins in the lumen (salting-in) and are substituted for strongly kosmotropic phosphate anions (salting out) during the natural fiber spinning process. 
Fig. 2.

Salt-induced aggregation of engineered and recombinantly produced major ampullate silklike proteins after incubation for $1 \mathrm{~h}$ at RT: induced by the presence of sodium chloride (grey circles) and by the presence of sodium phosphate (black circles), the concentration regime required to aggregate the proteins is indicated by striped boxes. (A) (AQ) ${ }_{12} \mathrm{NR3}$ (wild type). (B) (AQ) ${ }_{12} \mathrm{NR3}$ (D93A). (C) (AQ) ${ }_{24} \mathrm{NR3}$ (wild type). (D) (AQ) ${ }_{24}$. (E) A comparison of the degree of aggregation of our spider silk proteins with and without shear; induced in the presence of $50 \mathrm{mM}$ sodium chloride (grey bars), or $500 \mathrm{mM}$ sodium chloride (black bars).

\section{Figure options}

\subsection{The effect of shear on protein aggregation}

During the passage of the spinning dope from the lumen through the spinning duct to the spigot (the point at which the fiber exits the animal), the dope is exposed to shear forces which are known to encourage aggregation in a variety of globular and fibrillar proteins (Bekard and Dunstan, 2009, Cromwell et al., 2006, Hamilton-Brown et al., 2008, Hill et al., 2006, Vezy et al., 2009, Yamaura et al., 1982 and Yamaura et al., 1985); we were therefore keen to find out if shear forces have an effect upon the aggregation of our recombinantly produced MA silk-like proteins in vitro.

Our aggregation assays in the presence of shear forces (as the silk proteins are exposed to in the duct during fiber spinning) show that the extent of protein aggregation is dramatically increased in relation to corresponding assays in the absence of shear, in the presence of both low and high concentrations of salt; moreover, the aggregates formed after longer periods of exposure to shear were fibrous with dimensions of $\mu \mathrm{m}$ to $\mathrm{mm}$ scale (Fig. 3). 

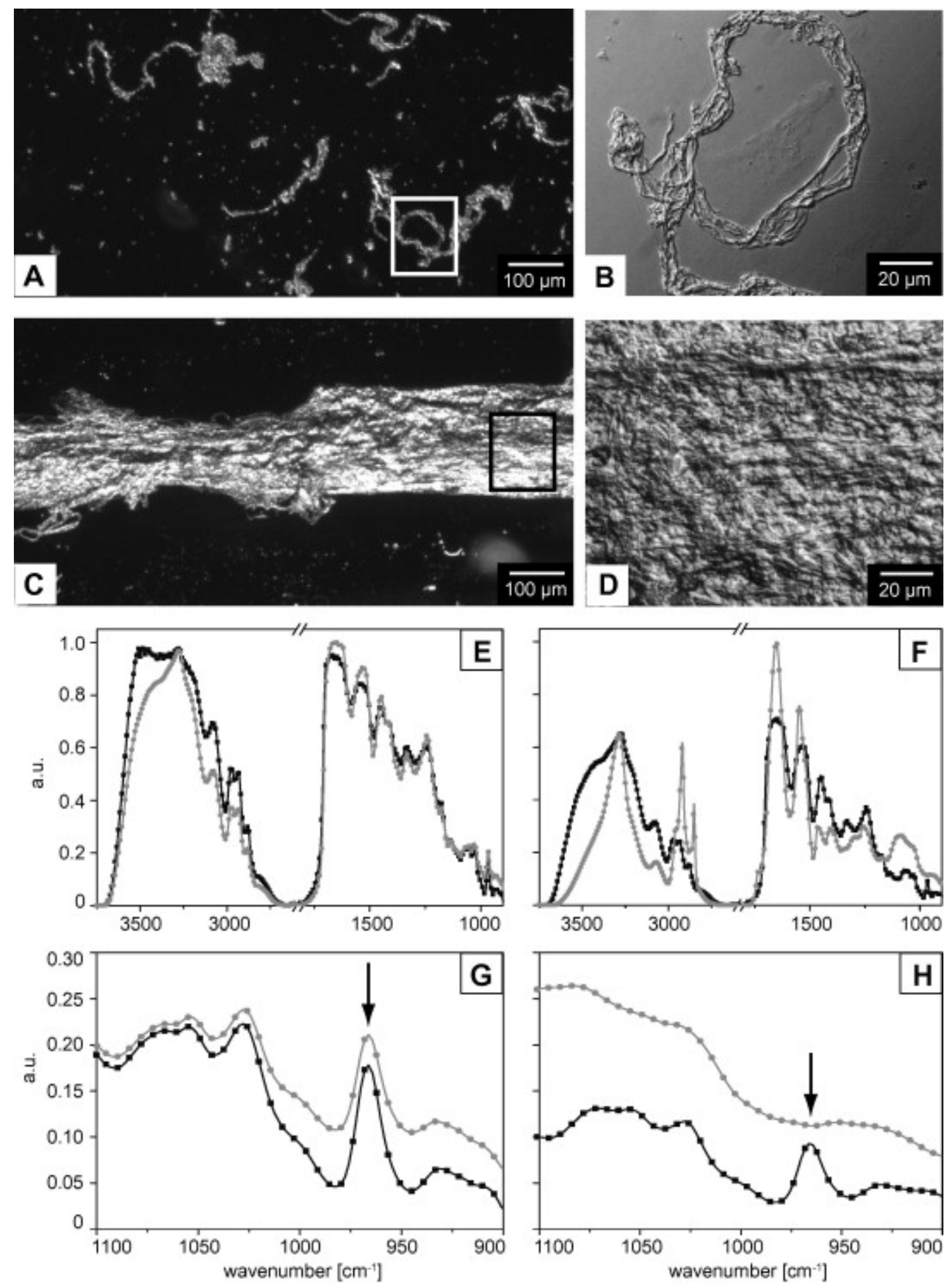

Fig. 3.

Shear-induced aggregation of our recombinantly produced major ampullate silk-like proteins. (A) Optical microscope image of aggregates produced by shear-induced aggregation of aqueous solutions of $(A Q)_{24}$. (B) Magnified image of the $(A Q)_{24}$ aggregates shown in A) (white frame). (C) Optical microscope image of well-defined fibrous aggregates produced by shear-induced aggregation of aqueous solutions of $(A Q){ }_{12} N R 3$. (D) Magnified image of one part of the ( $A Q)_{12} \mathrm{NR3}$ fiber (black frame). (E) Polarized FTIR spectra from (AQ) ${ }_{24}$ aggregates from $\mathrm{A} / \mathrm{B}$ recorded at $0^{\circ}$ (black circles) and $90^{\circ}$ (grey squares) relative to the long 
fiber axis. (F) Polarized FTIR spectra from $\mathrm{AQ}_{12} \mathrm{NR3}$ fibrils from $\mathrm{C} / \mathrm{D}$ recorded at $0^{\circ}$ (black circles) and $90^{\circ}$ (grey squares) relative to the long fiber axis. (G) Magnification of the region between 1100 and $900 \mathrm{~cm}^{-1}$ from the $A Q_{24}$ spectra $(E)$. The arrow indicates the characteristic polyalanine $\beta$-sheet band at around $960 \mathrm{~cm}^{-1}$ (Papadopoulos et al., 2009). (H) Magnification of the region between 1100 and $900 \mathrm{~cm}^{-1}$ from the $(A Q){ }_{12} \mathrm{NR} 3$ spectra $(F)$. The arrow indicates the characteristic polyalanine $\beta$-sheet band at around $960 \mathrm{~cm}^{-1}$.

\section{Figure options}

Particularly noteworthy is that water is absorbed from the dope during its passage along the spinning duct (Kojic et al., 2004 and Tillinghast et al., 1984), which increases the concentration of proteins and consequently increases the shear forces between the proteins in the dope due to strengthened hydrophobic interactions. This leads us to suggest that shear forces are likely to play a greater role than salt effects during the fiber spinning process in vivo (Casem et al., 2002, Knight and Vollrath, 2002, Perez-Rigueiro et al., 2001a and Perez-Rigueiro et al., 2001b).

\subsection{The role of the C-terminal NR domain in fiber storage and assembly}

It is widely accepted that higher order supramolecular assemblies are required to achieve silk protein storage at high concentrations within the lumen, and as noted in the introduction, we have previously shown the highly conserved C-terminal NR domain to be a prerequisite of certain supramolecular self-assembly processes (manifested in the form of fully reversible lower critical solubilisation temperature behavior) of our recombinantly produced proteins (Exler et al., 2007). Interestingly, our transmission electron microscope studies of freshly dialyzed solutions of $(A Q){ }_{12} N R 3$ show evidence of vesicle-like supramolecular assemblies (of $n m$ to $\mu \mathrm{m}$ scale), which is not the case for (AQ) ${ }_{24}$, a protein of similar molecular weight without the C-terminal NR domain (Fig. 4), which has also been observed by light microscopy in a previous study (Rammensee et al., 2008).
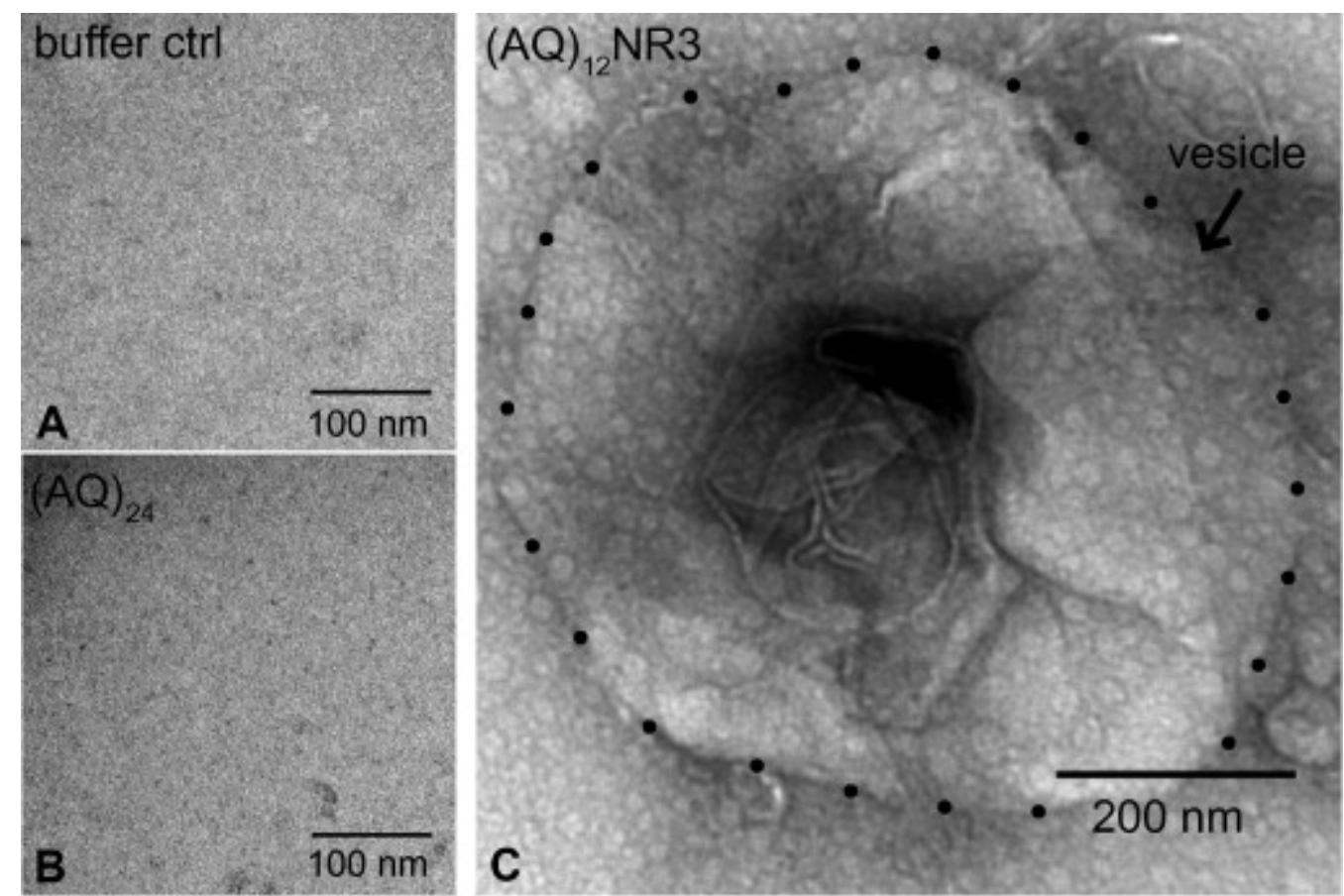
Fig. 4.

Images obtained via transmission electron microscopy. (A) Dialysis buffer. (B) Freshly dialyzed solutions of $(A Q)_{24}$. (C) Freshly dialyzed solutions of $(A Q)_{12} N R 3$, showing evidence of higher order supramolecular assemblies.

\section{Figure options}

Our salt-induced aggregation studies revealed no significant differences in the behavior of $(A Q){ }_{12} N R 3$ and $(A Q)_{24}$ in the presence of sodium chloride, whereas in the presence of sodium phosphate (>200 mM) (AQ) $)_{24}$ is much more prone to aggregation (Fig. 2A-D) suggesting that the C-terminal NR domain dependent supramolecular assemblies are stabilized to a certain degree against aggregation. Shear stress had a even pronounced effect on protein aggregation (Fig. 2E). Furthermore, exposure of solutions of $(A Q)_{24}$ to shear stress resulted in the formation of ill-defined $\beta$-sheet rich aggregates (Fig. $3 A$ and $B$ and Supplementary Table 1 ), whereas exposure of solutions of $(A Q){ }_{12} N R 3$ to shear stress yielded relatively well-defined fibrous aggregates which optical microscopy revealed to be composed of ordered (aligned) bundles of long fibrous aggregates (Fig. $3 \mathrm{C}$ and D). Interestingly, polarized Fourier Transform Infrared Spectra recorded at two different orientations $\left(0^{\circ}\right.$ and $90^{\circ}$ relative to the long axis of the fibrous aggregates) showed that the $\beta$-sheets within the fibrous aggregates of $(A Q)_{24}$ are randomly aligned, whereas the $\beta$-sheets within the fibrous aggregates of $(A Q)_{12} N R 3$ were predominantly aligned with the long axis of the fibers (in analogy to naturally spun fibers (Boulet-Audet et al., 2008, Lefevre et al., 2007a, Rousseau et al., 2009 and Rousseau et al., 2004)) due to a controlled assembly process (Fig. $3 \mathrm{E}$ and F) (Hagn et al., in press). This finding was further confirmed by FTIR in the region between 1100 and $900 \mathrm{~cm}^{-1}$ where specific signals for $\beta$ polyalanine crystals ( $964 \mathrm{~cm}^{-1}$ ) can be observed, as reported recently (Papadopoulos et al., 2009). Interestingly, a clear difference at the two employed angles using the polarizer can be seen for $(\mathrm{AQ})_{12} \mathrm{NR3}$ aggregates (Fig. $\left.3 \mathrm{H}\right)$, while there is no spectral difference for the $(\mathrm{AQ})_{24}$ aggregates, pointing out that the polyalanine crystals are oriented in the fibers formed from the protein with the NR domain, but not in the fibers formed from the protein without the NR domain. These findings suggest that the C-terminal NR domain controls both the storage of the proteins (by increasing their solubility and/or deterring undesirable aggregation events) and fiber formation (by facilitating controlled protein assembly into fibers upon demand).

\subsection{The role of the $\mathrm{N}$-terminal NR domain in fiber storage and assembly}

The N-terminal NR domains of silk proteins have been shown to be highly conserved between different spider species (Hedhammar et al., 2008, Lin et al., 2009, Motriuk-Smith et al., 2005 and Rising et al., 2006). However, due to a lack of any published sequence data of the $\mathrm{N}$ terminal NR domains of MA silk proteins of Araneus diadematus, this domain was not included in our engineered protein constructs. Despite this fact, our in vitro salt-induced aggregation assays with proteins with higher molecular weights and with longer repetitive sequence elements ((AQ) ${ }_{24} N R 3$ as opposed to (AQ) ${ }_{12} \mathrm{NR} 3$ ) showed them to be more prone to aggregation ( Fig. 2), which leads us to speculate that the N-terminal NR domain might also have an effect on higher order supramolecular assembly of silk proteins and therefore play an important role in protein storage and fiber assembly 
in vivo, as the natural proteins are larger than our recombinantly produced analogues ( Guerette et al., 1996 and Huemmerich et al., 2004b).

\section{Conclusions}

Our salt-induced aggregation assays clearly demonstrate that chloride (which is present in the lumen during silk protein storage) does not induce significant levels of protein aggregation, whereas phosphate (present in the spinning duct) does induce significant levels of protein aggregation, due to the strongly kosmotropic nature of the phosphate anion. Our shear-induced aggregation assays clearly show that shear forces are likely to play a greater role than salt effects during the fiber spinning process in vivo, and moreover, a key role in the alignment of the secondary structural elements within the fibers (which controls their mechanical properties). Our transmission electron microscope studies show that the C-terminal NR domain is a prerequisite for higher order supramolecular assembly of the proteins, which is important for both protein storage and the controlled assembly of fibers. Finally, we speculate that the N-terminal NR domains also play a role in protein storage (and potentially fiber formation).

\section{Acknowledgments}

We gratefully acknowledge the help of Stefan Geimer (Universität Bayreuth) for assistance with the transmission electron microscopy studies. We also acknowledge Franz Hagn and Horst Kessler (Technische Universität München) for supplying us with primers for the D93A mutants. L.E. acknowledges financial support from the German Federal Ministry of Education and Research (Bundesministerium für Bildung und Forschung, BMBF 13N9736). J.G.H. acknowledges financial support from the Alexander von Humboldt Foundation. M.H acknowledges financial support from the 'Graduiertenförderung nach dem bayerischen Eliteförderungsgesetz' (Universitäten Bayern, e.V.). T.R.S. acknowledges financial support from the German Research Foundation (Deutsche Forschungsgemeinschaft, DFG SCHE 603/4-3) and the German Federal Ministry of Education and Research (Bundesministerium für Bildung und Forschung, BMBF 13N9736). This manuscript is in memoriam of Rainer Rudolph.

\section{References}

Aprhisiart, A., Vollrath, F., 1994. Design-features of the orb web of the spider, Araneus diadematus. Behavioral Ecology 5, 280-287.

Baldwin, R.L., 1996. How Hofmeister ion interactions affect protein stability. Biophysical Journal 71, 2056-2063.

Bekard, I.B., Dunstan, D.E., 2009. Shear-induced deformation of bovine insulin in couette flow. Journal of Physical Chemistry B 113, 8453-8457.

Bini, E., Knight, D.P., Kaplan, D.L., 2004. Mapping domain structures in silks from insects and spiders related to protein assembly. Journal of Molecular Biology

335, 27-40.

Boulet-Audet, M., Lefevre, T., Buffeteau, T., Pezolet, M., 2008. Attenuated total 
reflection infrared spectroscopy: an efficient technique to quantitatively determine the orientation and conformation of proteins in single silk fibers. Applied Spectroscopy 62, 956-962.

Casem, M.L., Tran, L.P.P., Moore, A.M.F., 2002. Ultrastructure of the major ampullate gland of the black widow spider, Latrodectus hesperus. Tissue \& Cell 34, 427436.

Cromwell, M.E.M., Hilario, E., Jacobson, F., 2006. Protein aggregation and bioprocessing. Aaps Journal 8, E572-E579.

Exler, J.H., Hummerich, D., Scheibel, T., 2007. The amphiphilic properties of spider silks are important for spinning. Angewandte Chemie-International Edition 46, 3559-3562.

Foo, C.W.P., Bini, E., Hensman, J., Knight, D.P., Lewis, R.V., Kaplan, D.L., 2006. Role of $\mathrm{pH}$ and charge on silk protein assembly in insects and spiders. Applied Physics a-Materials Science \& Processing 82, 223-233.

Geisler, M., Pirzer, T., Ackerschott, C., Lud, S., Garrido, J., Scheibel, T., Hugel, T., 2008. Hydrophobic and Hofmeister effects on the adhesion of spider silk proteins onto solid substrates: an AFM-based single-molecule study. Langmuir 24, 1350-1355. Gerstein, M., Chothia, C., 1996. Packing at the protein-water interface. Proceedings of the National Academy of Sciences of the United States of America 93, 1016710172.

Gosline, J.M., Guerette, P.A., Ortlepp, C.S., Savage, K.N., 1999. The mechanical design of spider silks: from fibroin sequence to mechanical function. Journal of Experimental Biology 202, 3295-3303.

Guerette, P.A., Ginzinger, D.G., Weber, B.H.F., Gosline, J.M., 1996. Silk properties determined by gland-specific expression of a spider fibroin gene family. Science 272, 112-115.

Gurau, M.C., Lim, S.M., Castellana, E.T., Albertorio, F., Kataoka, S., Cremer, P.S., 2004. On the mechanism of the Hofmeister effect. Journal of the American Chemical Society 126, 10522-10523.

Hagn, F., Eisoldt, L., Hardy, J.G., Vendrely, C., Murray, C., Scheibel, T., Kessler, H., in press. A highly conserved spider silk domain acts as a molecular switch that controls fibre assembly. Nature.

Hamilton-Brown, P., Bekard, I., Ducker, W.A., Dunstan, D.E., 2008. How does shear affect a beta fibrillogenesis? Journal of Physical Chemistry B 112, 16249-16252. Hardy, J.G., Scheibel, T.R., 2009a. Production and processing of spider silk proteins. Journal of Polymer Science Part A-Polymer Chemistry 47, 3957-3963.

Hardy, J.G., Scheibel, T.R., 2009b. Silk-inspired polymers and proteins. Biochemical Society Transactions 37, 677-681.

Hardy, J.G., Romer, L.M., Scheibel, T.R., 2008. Polymeric materials based on silk proteins. Polymer 49, 4309-4327.

Hedhammar, M., Rising, A., Grip, S., Martinez, A.S., Nordling, K., Casals, C., Stark, M., Johansson, J., 2008. Structural properties of recombinant nonrepetitive and repetitive parts of major ampullate spidroin 1 from Euprosthenops australis: implications for fiber formation. Biochemistry 47, 3407-3417.

Heim, M., Keerl, D., Scheibel, T., 2009. Spider silk: from soluble protein to 
extraordinary fiber. Angewandte Chemie-International Edition 48, 3584-3596.

Hijirida, D.H., Do, K.G., Michal, C., Wong, S., Zax, D., Jelinski, L.W., 1996. C-13 NMR of Nephila clavipes major ampullate silk gland. Biophysical Journal 71, 3442-3447. Hill, E.K., Krebs, B., Goodall, D.G., Howlett, G.J., Dunstan, D.E., 2006. Shear flow induces amyloid fibril formation. Biomacromolecules 7, 10-13.

Horinek, D., Serr, A., Geisler, M., Pirzer, T., Slotta, U., Lud, S.Q., Garrido, J.A., Scheibel, T., Hugel, T., Netz, R.R., 2008. Peptide adsorption on a hydrophobic surface results from an interplay of solvation, surface, and intrapeptide forces.

Proceedings of the National Academy of Sciences of the United States of America 105, 2842-2847.

Huang, W., Lin, Z., Sin, Y.M., Li, D., Gong, Z., Yang, D., 2006. Characterization and expression of a cDNA encoding a tubuliform silk protein of the golden web spider Nephila antipodiana. Biochimie 88, 849-858.

Huemmerich, D., Scheibel, T., Vollrath, F., Cohen, S., Gat, U., Ittah, S., 2004a. Novel assembly properties of recombinant spider dragline silk proteins. Current

Biology 14, 2070-2074.

Huemmerich, D., Helsen, C.W., Quedzuweit, S., Oschmann, J., Rudolph, R., Scheibel, T., 2004b. Primary structure elements of spider dragline silks and their contribution to protein solubility. Biochemistry 43, 13604-13612.

Ittah, S., Michaeli, A., Goldblum, A., Gat, U., 2007. A model for the structure of the Cterminal domain of dragline spider silk and the role of its conserved cysteine.

Biomacromolecules 8, 2768-2773

Ittah, S., Cohen, S., Garty, S., Cohn, D., Gat, U., 2006. An essential role for the Cterminal domain of a dragline spider silk protein in directing fiber formation.

Biomacromolecules 7, 1790-1795.

Jin, H.J., Kaplan, D.L., 2003. Mechanism of silk processing in insects and spiders.

Nature 424, 1057-1061.

Kim, J., Cremer, P.S., 2001. Elucidating changes in interfacial water structure upon protein adsorption. ChemPhysChem 2, 543-546.

Knight, D.P., Vollrath, F., 2001. Changes in element composition along the spinning duct in a Nephila spider. Naturwissenschaften 88, 179-182.

Knight, D.P., Vollrath, F., 2002. Biological liquid crystal elastomers. Philosophical Transactions of the Royal Society of London Series B-Biological Sciences 357, 155-163.

Kojic, N., Kojic, M., Gudlavalleti, S., McKinley, G., 2004. Solvent removal during synthetic and Nephila fiber spinning. Biomacromolecules 5, 1698-1707.

Lefevre, T., Rousseau, M.E., Pezolet, M., 2007a. Protein secondary structure and orientation in silk as revealed by Raman spectromicroscopy. Biophysical Journal 92, 2885-2895.

Lefevre, T., Boudreault, S., Cloutier, C., Pezolet, M., 2008. Conformational and orientational transformation of silk proteins in the major ampullate gland of Nephila clavipes spiders. Biomacromolecules 9, 2399-2407.

Lefevre, T., Leclerc, J., Rioux-Dube, J.F., Buffeteau, T., Paquin, M.C., Rousseau, M.E., Cloutier, I., Auger, M., Gagne, S.M., Boudreault, S., Cloutier, C., Pezolet, M., 2007b. 
Conformation of spider silk proteins in situ in the intact major ampullate gland and in solution. Biomacromolecules 8, 2342-2344.

Lesk, A.M., Chothia, C., Ramsay, W., Foster, R., Ingold, C., 1980. Solvent accessibility, protein surfaces, and protein folding. Biophysical Journal 32, 35-47.

Levy, E.D., Pereira-Leal, J.B., Chothia, C., Teichmann, S.A., 2006. 3D complex: a structural classification of protein complexes. Plos Computational Biology 2, 1395-1406.

Lewis, R.V., 2006. Spider silk: ancient ideas for new biomaterials. Chemical Reviews 106, 3762-3774.

Lin, L.H., Edmonds, D.T., Vollrath, F., 1995. Structural-engineering of an orb-spiders web. Nature 373, 146-148.

Lin, Z., Huang, W.D., Zhang, J.F., Fan, J.S., Yang, D.W., 2009. Solution structure of eggcase silk protein and its implications for silk fiber formation. Proceedings of the National Academy of Sciences of the United States of America 106, 89068911.

Motriuk-Smith, D., Smith, A., Hayashi, C.Y., Lewis, R.V., 2005. Analysis of the conserved $\mathrm{N}$-terminal domains in major ampullate spider silk proteins.

Biomacromolecules 6, 3152-3159.

Papadopoulos, P., Ene, R., Weidner, I., Kremer, F., 2009. Similarities in the structural organization of major and minor ampullate spider silk. Macromolecular Rapid Communications 30, 851-857.

Pegram, L.M., Record, M.T., 2008. Thermodynamic origin of Hofmeister ion effects. Journal of Physical Chemistry B 112, 9428-9436.

Perez-Rigueiro, J., Elices, M., Llorca, J., Viney, C., 2001a. Tensile properties of silkworm silk obtained by forced silking. Journal of Applied Polymer Science 82, 1928-1935.

Perez-Rigueiro, J., Elices, M., Llorca, J., Viney, C., 2001b. Tensile properties of Attacus atlas silk submerged in liquid media. Journal of Applied Polymer Science 82, 5362.

Pirzer, T., Geisler, M., Scheibel, T., Hugel, T., 2009. Single molecule force measurements delineate salt, $\mathrm{pH}$ and surface effects on biopolymer adhesion. Physical Biology 6. doi:10.1088/1478-3975/6/2/025004.

Rammensee, S., Slotta, U., Scheibel, T., Bausch, A.R., 2008. Assembly mechanism of recombinant spider silk proteins. Proceedings of the National Academy of Sciences of the United States of America 105, 6590-6595.

Rising, A., Hjalm, G., Engstrom, W., Johansson, J., 2006. N-terminal nonrepetitive domain common to dragline, flagelliform, and cylindriform spider silk proteins. Biomacromolecules 7, 3120-3124.

Rossmann, M.G., Argos, P., 1981. Protein folding. Annual Review of Biochemistry 50, 497-532.

Rousseau, M.E., Lefevre, T., Pezolet, M., 2009. Conformation and orientation of proteins in various types of silk fibers produced by Nephila clavipes spiders.

Biomacromolecules 10, 2945-2953.

Rousseau, M.E., Lefevre, T., Beaulieu, L., Asakura, T., Pezolet, M., 2004. Study of protein conformation and orientation in silkworm and spider silk fibers using 
Raman microspectroscopy. Biomacromolecules 5, 2247-2257.

SenGupta, S., Scheibel, T., 2007. Folding, self-assembly and conformational switches of proteins. In: Zbilut, J.P., Scheibel, T. (Eds.), Protein Folding-Misfolding: Some Current Concepts of Protein Chemistry. Nova Publishers, New York. pp. 1-34. Stark, M., Grip, S., Rising, A., Hedhammar, M., Engstrom, W., Hjalm, G., Johansson, J., 2007. Macroscopic fibers self-assembled from recombinant miniature spider silk proteins. Biomacromolecules 8, 1695-1701.

Tillinghast, E.K., Chase, S.F., Townley, M.A., 1984. Water extraction by the major ampullate duct during silk formation in the spider, Argiope aurantia Lucas. Journal of Insect Physiology 30, 591-596.

Vezy, C., Hermanson, K.D., Scheibel, T., Bausch, A.R., 2009. Interfacial rheological properties of recombinant spider-silk proteins. Biointerphases 4, 43-46.

Vollrath, F., Knight, D.P., 1999. Structure and function of the silk production pathway in the spider Nephila edulis. International Journal of Biological Macromolecules 24, 243-249.

Vollrath, F., Knight, D.P., 2001. Liquid crystalline spinning of spider silk. Nature 410, 541-548.

Yamaura, K., Okumura, Y., Matsuzawa, S., 1982. Mechanical denaturation of high polymers in solutions. 36 . Flow-induced crystallization of bombyx-mori I silk fibroin from the aqueous-solution under a steady-state flow. Journal of Macromolecular Science-Physics B21, 49-69.

Yamaura, K., Okumura, Y., Ozaki, A., Matsuzawa, S., 1985. Flow-induced crystallization of bombyx-mori I silk fibroin from regenerated aqueoussolution and spinnability of its solution. Applied Polymer Symposia 205, 220.

Zbilut, J.P., Scheibel, T., Huemmerich, D., Webber, C.L., Colafranceschi, M., Giuliani, A., 2005. Spatial stochastic resonance in protein hydrophobicity. Physics Letters A 346, 33-41.

Zbilut, J.P., Scheibel, T., Huemmerich, D., Webber, C.L., Colafranceschi, M., Giuliani, A., 2006. Statistical approaches for investigating silk properties. Applied Physics a-Materials Science \& Processing 82, 243-251.

Zhang, Y.J., Cremer, P.S., 2006. Interactions between macromolecules and ions: the Hofmeister series. Current Opinion in Chemical Biology 10, 658-663.

Zhang, Y.J., Furyk, S., Bergbreiter, D.E., Cremer, P.S., 2005. Specific ion effects on the water solubility of macromolecules: PNIPAM and the Hofmeister series. Journal of the American Chemical Society 127, 14505-14510. 